\title{
Sciendo
}

Administration, vol. 68, no. 4 (2020), pp. 161-180

doi: 10.2478/admin-2020-0029

\section{Quality assurance in Irish schools: Inspection and school self-evaluation}

\author{
Gerry McNamara, Joe O'Hara, Martin Brown, Irene Quinn \\ Centre for Evaluation, Quality and Inspection (EQI), \\ Institute of Education, Dublin City University, Ireland
}

\begin{abstract}
In this paper, we provide an overview of the development of school inspection in Ireland over the past twenty years using the analytic and critical lens developed by Richard Boyle in partnership with the current authors. The paper is fundamentally a reflection on the nature, purpose and operation of evaluation in the Irish public sector through the lens of education. The paper provides a historical overview of developments in the linked areas of school evaluation and inspection, and goes on to explore how the implementation of this mode of quality assurance has influenced, and been influenced by, a wide range of policy actors. The argument made is that education has embedded a culture of evaluation in a unique yet systemically resonant manner and that a reflection on this reality will help illuminate our understanding of the role of evaluation across the public sector as a whole.
\end{abstract}

Keywords: School evaluation, school inspection, accountability, quality assurance, reform

\section{Introduction}

Throughout his distinguished career, Richard Boyle has authored, edited and published some of the most significant works charting the evolution of public sector management and reform in Ireland. 
Through this work, he has managed to reflect on the changing understandings of key concepts underpinning management practice within the public sector whilst at the same time offering an incisive critique of the operationalisation of these evolving concepts in real time. This combination of high-level conceptual explanation and a clear analysis of the implications of these changes in thinking on daily practice is at the heart of his work in the field of education, and more specifically that of educational evaluation. In the course of the past fifteen years, writing in partnership with the current authors, Richard Boyle has provided a unique and systemically important analysis of changes in Ireland's understanding of the function and role of evaluation through a rigorous engagement with the emerging system of inspection in Irish schools (Boyle et al., 2012, 2020; McNamara et al., 2008, 2009). Drawing on his wide academic and professional hinterland developed during his time with the Institute of Public Administration (IPA), his work in the field of school evaluation and inspection showcases his unique combination of analytic and descriptive skills. In this paper, we will seek to provide an overview of the development of school inspection in Ireland over the past twenty years using the analytic and critical lens developed by Richard Boyle in partnership with the current authors, and hopefully demonstrate how his work has resonated far beyond the confines of the IPA, having a significant impact on provision within the school system in Ireland. The paper is fundamentally a reflection on the nature, purpose and operation of evaluation in the Irish public sector through the lens of education. The argument made is that education has embedded a culture of evaluation in a unique yet systemically resonant manner and that a reflection on this reality will help illuminate our understanding of the role of evaluation across the public sector as a whole.

\section{Background}

In Ireland in the decades preceding the year 2000, the notion of quality assurance had not yet migrated into compulsory-level education, in comparison to other sectors such as the healthcare sector. School accountability and supervision was not high on the agenda of Irish government architects of policy and practice, and was assumed to be a matter for the Inspectorate, a division of the Department of Education and Science (DES). ${ }^{1}$ Although school inspection dated back to the

1 The department changed its title in 2010 to the Department of Education and Skills. In this paper, 'DES' refers to both titles. 
nineteenth century and the figure of the inspector (or cigire in Irish) was well known and respected, by the 1990s inspection had a much lower profile (Brown et al., 2016a). Still extant, but to a limited degree in primary schools, it had almost completely disappeared from the post-primary sector. This happened for a variety of reasons, such as strong resistance to evaluation by the teacher unions and, primarily, the allocation of a considerable proportion of inspection resources to the preparation and quality assurance of state examinations, namely the upper secondary Leaving Certificate Examination.

The 1990s saw significant growth in interest in the concepts of quality and evaluation in education, at first internationally and subsequently in Ireland. The roots of this development are a contested area, and we will examine them below, but undoubtedly the perceived relationship between 'quality education' and economic growth and competitiveness was central. For example, in the case of England, Ehren \& Perryman (2018, p. 945), among many scholars, argue that, from that time on, quality education came to be considered as a matter of more pressing public interest than it was previously and, 'understandably, considerable effort was now paid to the quality of schools and the improvement of the levels of educational attainment in society'.

The Education Act of 1998 gave the Inspectorate, for the first time in the history of Irish education, a legislative remit to "evaluate the education standards in schools or centres... to promote excellence in the management of, teaching in and the use of support services by schools', and the DES began active work on the design and testing of a quality assurance system for Irish schools. The framework envisioned was summarised in a document entitled Looking at Our School: An Aid to Self-Evaluation in Second Level Schools (LAOS), published in 2003 (Department of Education and Science, 2003). The preamble gives a clear explanation of the reasons for, and the philosophy underpinning, the new approach to quality assurance, stating:

Ireland, along with other European countries, is adopting a model of quality assurance that emphasises school development planning through internal school review and self-evaluation with the support of external evaluation carried out by the Inspectorate. (Department of Education and Science, 2003, p. viii) 
The next section of this paper provides an account of the roots and influences underpinning these developments in the 1990s. We then consider subsequent developments in quality assurance in education, and in particular the structure and methodology of school inspection and school self-evaluation (SSE) as it has evolved in Ireland since the year 2000. In the final section, we provide a brief appraisal of the evidence around the vexed question of whether all this effort to achieve 'quality' has had any discernible positive impact on schools and learners.

\section{The history and context of school evaluation policy}

The influential sociologist Stephen Ball (1993, 2003, 2012; Ball et al., 2011, 2012) reminds us that policy has a history, and much of the current policy and practice regarding quality assurance and the evaluation of performance in the Irish school system dates to the 1990s. What Bowe et al. (2017, p. 20) refer to as the 'context of influence' concerning policy formation in this area of Irish education was at that time - it is widely agreed by both critics and proponents largely international. New concepts in public sector governance such as New Public Management, managerialism, performativity, accountability, devolution of decision-making, and evidence-based practice came onto the agenda, driven to a significant degree by influential supranational bodies such as the OECD, the Standing International Conference of Inspectorates (SICI) and the European Commission (McConnell, 2010; Minogue, 1983).

In education, internationally, these policies manifested themselves in two interconnected ways - the devolution of greater autonomy to schools and the restructuring or (in the many countries that had no history of inspection) the creation of inspection systems. Thus, schools were, in theory at least, to be granted greater autonomy over key areas of their work (including, in some cases, teacher pay and conditions) while at the same time being made more accountable for performance through greater external 'surveillance' (OECD, 2013, 2019).

In Ireland it seemed that these developments might manifest in similar ways. For example, school autonomy and accountability loom large as themes in the Education White Paper of 1995, and the Education Act, 1998, mandated whole school development planning (SDP), with development plans to be formally devised by schools but made available for scrutiny by inspectors. The Act also clearly defined, for the first time, the role and responsibility of the Inspectorate and 
this, taken together with SDP, charted the way to a model of quality assurance involving external inspection linked to internal research, planning and decision-making.

Some education academics in Ireland and beyond, particularly those on the left, did not doubt that these initiatives represented intrusive and threatening policies similar to those of the widely reviled and dreaded OFSTED inspection regime in England. Sugrue (2006, p. 3 ) traces the evolution of what he calls performativity and accountability policy and practice over the previous decade in Ireland. He outlines the effects of economic growth and, with it, the development, he suggests, of materialism and consumerism in Irish society and how this has impacted on educational policy. He argues that we have seen an increase in performativity agendas and suggests that 'the language of efficiency shapes our public as well as our private lives'. Perryman (2006, p. 150), drawing on the work of Foucault (1995), suggests that inspections can be characterised as the panoptic gaze of the accountability police.'

Lynch et al. (2012) also suggest that the 1990s saw the introduction of new managerialism into education in Ireland. Ireland, they allege, had entered a new age of policy discourse: the age of modernisation and neoliberalism. According to Lynch et al. (2012), a 'spirit of capitalism' was entering Irish society, leading to the introduction of a new mode of governance. New managerialism, they claimed, had led to performance indicators, systems of accountability and strategic plans in Irish education. Lynch et al. (2012, p. 14) further contend that market-led models of control and regulation had become dominant in the public sector, and that the new type of management had very different values and practices to those of professional responsibility and service which had characterised education heretofore. According to Lynch (2014, p. 3) 'new managerialism's prioritisation of efficiency and effectiveness' is often at the 'expense of more broadly based moral and social values related to care, autonomy, tolerance, respect, trust and equality'.

However, Ball (1993) also suggests that policy, as well as having a history, equally has a context. The context in which these policy initiatives were introduced in Ireland was one of 'social partnership', where public sector reform was a matter of negotiation and agreement between government and the public sector unions. It was also one where the teacher unions were among the most powerful and influential of these organisations. Thus, the notion that the more extreme manifestations of neoliberal accountability regimes could 
have been imposed in Ireland is far-fetched and wildly overstated. There is no indication that senior policymakers either envisioned or even desired such an outcome. Indeed, according to Hogan (2019, p. 6), 'that decade became one of intense developments that saw Ireland take a largely different path in educational policy to the neoliberal path taken in most of the English-speaking world'.

Much of the work undertaken by Boyle in the period from 2000 onwards explores how the Irish state adapted to and adopted new modes of thinking in public sector management and reform, emphasising the broadly evolutionary rather than revolutionary nature of these developments (Boyle et al., 2020). The model of school evaluation which has gradually emerged is very much in the European mainstream, involving a limited degree of school autonomy operationalised through SSE coupled with a 'low stakes' form of external inspection. What has emerged has been much more influenced by the seminal work of MacBeath (1999) in Scotland in the 1990s than by more draconian models or theories in England or elsewhere. As Croxford et al. (2009) suggest, the Scottish selfevaluation model of quality assurance has had a substantial influence on the work of SICI and in turn has influenced developments in many countries, not least Ireland. Even the OECD, often alleged to be a proponent of hard-nosed monitoring of schools, attributes the success of evaluation in Ireland to the fact that the system is 'positive, affirming and developmental rather than punitive or negative' (OECD, 2013, p. 13). The purpose of school evaluation in Ireland was described by Chief Inspector Harold Hislop (2012, p. 2) as follows: 'our ultimate goal is for schools to conduct their own evaluations transparently and accurately and for inspectors to visit these schools to evaluate the school's own self-evaluation'. This is hardly an indication of plans for intrusive and professionally demeaning interventions in schools. It is also noteworthy that while the unions have mandated non-cooperation with inspection and SSE from time to time, this has been used as a weapon in other disputes rather than as resistance to the regime which is emerging.

Nonetheless, with regard to this debate, it is only fair to say that critics may have had some cause for suspicion. It is interesting to note that as the school evaluation system has evolved and has become an excepted facet of school life, it has undoubtedly acquired elements which left-wing scholars might well perceive to be part of the neoliberal agenda. These include a much greater emphasis on evidence and data, including examination results and standardised test 
scores, both in setting targets for individual students and in the making of evaluative judgements about the performance of schools, and also in the increasing recognition of the rights of parents and students to have an input into school evaluation (Brown et al., 2013, 2016a, 2016b). The next section will chart, through a close analysis of policy documents, the gradual evolution of the school evaluation system since 2003.

\section{A toe in the water: Whole School Evaluation, 2003-12}

As indicated in the introduction above, school inspection had never completely disappeared from Irish education but had become largely moribund. The rebirth (or, in many countries, birth) of interest in effective inspection, including an element of internal SSE, was an international phenomenon which influenced Ireland in the late 1990s. From 1996 to 1999, the Irish Inspectorate conducted a pilot project in twenty schools testing a new, more elaborate and structured inspection framework, called Whole School Evaluation (WSE) (McNamara \& O'Hara, 2012). The response to this was encouraging, but due to a series of industrial disputes (not directly related to the proposed system of evaluation), the implementation of the new quality assurance era did not begin until 2003. In that year, the DES issued LAOS, a substantial framework explaining to schools how the new quality assurance system would work. Although, as we shall see, further policy documents issued in the subsequent fifteen years refined and developed the system considerably, the basic structure of external monitoring by the Inspectorate, complemented by internal SSE, remains fundamentally unchanged.

The LAOS 2003 document finally set out a clear framework within which school inspections and the related new notion of SSE would be conducted, and was considerably influenced by the work of MacBeath (1999) and by concerns that, given the controversial nature of school inspection in Ireland and the suspicions of the teacher unions, a lowstakes, unthreatening approach was appropriate. In the years that followed, both inspection and SSE became well established and mostly uncontroversial. However, in the years between 2003 and 2016 academic critiques and, it may be inferred, a desire by the Inspectorate to, as it were, tighten up the accountability element of inspection led to revised policy documents and some considerable changes to practice. 
In LAOS, schools were introduced to the concept of SSE, which, due primarily to the work of MacBeath, had gained considerable currency in an increasing number of education systems. In the foreword, the then chief inspector tells us that LAOS was designed to 'promote excellence'. It was devised in consultation with the 'education partners' and was to establish a model of school evaluation in which external inspection and SSE would be entwined. Regarding quality in schools, 'efficiency and effectiveness' were to be formally evaluated both through external WSE and SSE conducted internally in schools, but following closely a template provided by the Inspectorate. The Education Act, 1998, had outlined the schools' role in planning and how quality assurance is necessary to 'monitor and assess the quality' of schools. LAOS detailed how school improvement involves both external review and internal self-evaluation and exactly how these processes were to be conducted. This represented a notable shift in emphasis by the Inspectorate in that, previously, inspection had been perceived and conducted as an entirely external activity. As indicated above, LAOS provides a model based very much on the theories of MacBeath (1999, p. 20), who sees 'the role of external evaluation as being to ensure that internal improvement is conducted effectively'.

LAOS describes two types of external inspections - WSE and subject inspections. WSE involved a team of inspectors conducting a root and branch inspection of each school, at intervals, it was hoped, of three to five years. Subject inspections were of single subjects and subject departments and usually involved a smaller inspection team. The latter occurred more regularly, and most schools could expect at least one inspection of a subject in most years. In between these external inspections, schools were expected to be taking particular areas of their work and subjecting them to close scrutiny. This process was to involve the collection and analysis of evidence, the creation of improvement plans with specific objectives and targets, and the monitoring of these objectives. In theory, this internal self-evaluation was to feed into external inspection by providing evidence of improvement initiatives to inspectors.

In the years subsequent to 2003, McNamara \& O'Hara (2002, 2004, 2005, 2006, 2008c, 2012), McNamara et al. (2011) and Brown (2013) conducted a series of evaluations with schools to analyse their perceptions of the new quality assurance system. On the whole, it was positively received, particularly the good relations which the Inspectorate had established with the schools (McNamara \& O'Hara, 
2008c). However, it also became clear that there were flaws in the process. On the inspection side, it was widely felt by school principals that WSE was very unwieldy, took too long and was overly focused on paperwork, particularly on compliance with regulations. Teachers valued being evaluated by an inspector but felt that the feedback, which was very much pitched at whole school and subject departmental level, was not as helpful as it might have been. Importantly, it was not at all clear to schools what, if any, follow-up would flow from an inspection, whether in terms of support and resources or even further inspection if faults were found. Other criticisms were that, in the early days, WSE reports were not available to the public, and even when this was rectified in 2005, the reports were vague and anodyne.

When it came to the SSE side of the process, most schools were simply lost - totally unprepared to undertake such a task. The biggest issue was that the quality of data available in schools to conduct any type of extensive SSE was poor, and the capacity of schools and teachers to engage in this activity was weak. McNamara \& O'Hara (2006, 2008a, 2008b, 2011, p. 12) remark that "no attempt is made to suggest who should collect and analyse the information or how data can be collected'. This lack of key data was a serious weakness, compounded by indications in the research that even where schools did collect and analyse performance or results data, the Inspectorate (probably through caution that such data could be used to compile league tables of schools or monitor individual teacher performance) did not encourage it. A second major criticism made by McNamara \& O'Hara (2008a) was that, while there were a very unwieldy set of 143 themes for self-evaluation outlined and a suggestion that schools rate themselves against these on a four-point scale, no criteria or set of standards as to what might count as good performance on these themes were defined. Finally, given that, at core, school evaluation is quite frequently conceptualised as a process involving all members of the school community, it was striking that there was a limited role provided for parents or pupils in the inspection or SSE process. Furthermore, the exact relationship between SSE and external inspection was not made clear, since SSE was not made a mandatory activity for schools. In conclusion, the overall outcome of these various evaluations might be summarised as one of system acceptance and admiration for the fact that a quality assurance mechanism had been introduced and consolidated in a volatile environment, but a recognition that it was a long way from being coherent and effective (McNamara \& O'Hara, 2008b). 
In the years following 2008, the Inspectorate sought to deal with some of these problems in a piecemeal fashion. WSE was streamlined as Whole School Evaluation - Management, Leadership and Learning (WSE-MLL), involving a smaller team and usually completed in two days. The DES describes this type of inspection as follows: 'during these inspections, we evaluate the quality of the school management and leadership, the quality of teaching, learning and assessment, and the school's own planning and self-review... we use slightly different processes in primary and post-primary schools; sometimes the inspection has a subject or curriculum focus and at other times, we concentrate on a range of different lessons across a wide range of subjects. We provide oral feedback to the school community at the end of these inspections, and we provide a printed report which is published on our website'. ${ }^{2}$

In addition, the Inspectorate also added two new inspection modalities, common in other jurisdictions but new to Ireland. These were 'incidental', that is to say unannounced or surprise, inspections, and 'risk-based' inspections in schools which were a cause of concern, for whatever reason, received additional inspection treatments'. These changes, we would suggest, represented a considerable strengthening of the inspection regime. They were indicative of growing confidence in the Inspectorate that inspection and quality assurance were firmly established in Irish schools, and that what McNamara \& O'Hara (2008a) described as the 'softly, softly' approach of the early years might safely be made more robust.

\section{The coming of age of SSE, 2012-20}

While the inspection reforms mentioned in the previous section certainly made the overall system more effective, SSE, the second pillar, as it were, remained very much the neglected relation. Some attempts to improve the capacity of schools to conduct self-evaluation had been made, mainly through limited training support, but, apart from a minority of schools where its potential was recognised, SSE remained largely peripheral. This was significantly altered by the publication of a new policy document in 2012, School Self-Evaluation Guidelines (Department of Education and Skills, 2012a).

The 2011-2016 programme for government (Government of Ireland, 2010) stated that SSE would be formalised, requiring schools

\footnotetext{
2 See www.education.ie
} 
to evaluate their performance year on year and publish information across a range of criteria. This, in fact, made SSE mandatory for the first time, although it had been in widespread use in schools, if to greatly varying degrees, since LAOS had first encouraged schools to self-evaluate. This represented a step-change in official attitudes to SSE and was followed by the introduction of a requirement that SSE was to be implemented by all schools using Inspectorate-devised SSE guidelines over the following three-year period. In this iteration of mandatory SDP and evaluation, SSE is defined as:

A collaborative, inclusive, reflective process of internal school review. During school self-evaluation the principal, deputy principal and teachers, under the direction of the board of management and the patron and in consultation with parents and pupils, engage in reflective enquiry on the work of the school. It is an evidence-based approach which involves gathering evidence from a range of sources and making judgements with a view to bringing about improvements in pupils' learning. (Department of Education and Skills, 2012b, p. 3)

Mirroring the work of MacBeath (1999) and the Scottish Inspectorate's SSE framework entitled How Good is Our School? (HM Inspectorate of Education, 2002), the DES required schools to address the following key questions with regard to an aspect or aspects of its work: 'How well are we doing?; How do we know?; How can we find out more?; What are our strengths?; What are our areas for improvement?; How can we improve?'

This is similar enough to the existing guidance on conducting SSE in Ireland and other jurisdictions, except that, crucially, schools were now told that between 2012 and 2016 their SSEs must focus each year on literacy and numeracy and one other curriculum area, and in each case must result in a concise school improvement plan, with clear and measurable targets (Brown et al., 2016b).

Again, recalling Ball (1993) and his precept that policy has a context, we can surmise that the context of the sudden seriousness accorded to SSE arose from the 'PISA shock' of that time, referring to the hugely influential OECD-run Programme for International Student Assessment, a comparative test of students' performance at fifteen years of age. In the previous year, the Irish results in PISA showed an unexplained and unexpected decline. This resulted in a flurry of initiatives to address this worrying outcome, including the 
rapid development of a DES literacy and numeracy strategy (Department of Education and Skills, 2012b). SSE provided an ideal tool to implement and monitor this initiative.

Also, although SSE was now to be mandatory, the Inspectorate made it more worthwhile for schools to engage seriously by, at last, clarifying that SSE work would be linked closely to school inspections: 'External evaluation processes such as the WSE will take increased account of the self-evaluation engaged in by schools' (Department of Education and Skills, 2012a, p. 13). As McNamara \& O'Hara (2012, p. 13) note, the original premise of the relationship between inspection and SSE posited in 2003 finally came to fruition in 2012, as 'the policy now is that school self-evaluation will act as a preparation for inspection but, more importantly, it is also to be the driving force for collaborative internal school improvement efforts'.

Importantly, however, it was also made clear in 2012 that, as well as being developmental in nature, SSE would have a strong internal accountability aspect. Chief Inspector Hislop (2012) suggested that over time SSE would 'create a genuine sense of and embed a culture of robust self-review and professional accountability in the school community'.

The mandatory nature of SSE 2012, the specific areas to be evaluated and the collection and use of data - particularly standardised tests and surveys of parental and student opinions - were significant developments of the much less prescriptive approach taken when SSE first appeared in LAOS 2003. In consequence, between 2012 and 2016, SSE became a much more prevalent and significant part of the life of schools. Through a mixture of necessity, experience and various initiatives, such as the creation of a dedicated DES website to support schools with SSE, the provision of SSE professional development opportunities by the Professional Development Service for Teachers, and the work of Shivaun O'Brien and colleagues at Dublin City University, schools gradually developed a greater capacity to self-evaluate.

In 2016 the Inspectorate issued Looking at Our School 2016, a revised version of the original LAOS 2003 policy, which encompassed the various changes that had been made in the intervening years but also included some crucial new developments.

While in LAOS 2003 inspectors and schools were to make evaluative judgements of performance, LAOS 2016 defines a detailed 'quality framework' across a range of 'domains'. The framework maps out a common set of standards and a common language that schools 
can use to make their own judgements regarding their effectiveness and that are also the criteria against which the Inspectorate forms their evaluations. As has already been noted, LAOS 2003 was a very complex document containing 143 'themes for self-evaluation'. In contrast, the modified and more succinct LAOS 2016 has two dimensions - teaching and learning, and leadership and management. Each dimension has four domains, with each domain having four standards. For example, the quality framework for primary schools outlines 'statements of practice for both teaching and learning and leadership and management'. A definition of what counts as 'effective or highly effective practice' is then provided in relation to each set of standards (Brown et al., 2020).

The language describing the difference between effective and highly effective practice is carefully nuanced, with the former tending somewhat towards aspirational language about what might be done and the latter a confirmation of what is being done (Brown et al., 2017). The terminology and language used for the statements of practice for the highly effective schools are more descriptive and powerful. For example, those for effective practice acknowledge how school leaders are 'aware, recognise and seek to ensure'. In contrast, in highly effective practice, they are acknowledged with terminology such as 'identity, inspire and empower'. These are, of course, very qualitative judgements but are meant, we are told, to be validated by a wide range of evidence.

It is evident throughout the document that SSE is not going to supersede inspection and that school inspections are still to be part of the evaluation toolkit, with inspectors continuing to carry out forensic examinations of schools, gathering as much information and evidence as possible during their visits.

Finally, with regard to LAOS 2016, the SSE regime mandated to be implemented in schools since 2012 remained largely unchanged except for some further streamlining in response to complaints that it was very time-consuming. However, the criteria to be used by schools to make judgements on the quality of teaching and learning are exactly the same as those used by the DES when carrying out school inspections, creating a genuinely interconnected mode of evaluation between the Inspectorate and schools.

From 2016 on, schools were encouraged to undertake 'modest SSE projects', choosing two or three 'aspects of the curriculum' over the period to June 2020, thus allowing schools a good deal of latitude as to what areas they might choose to evaluate (O'Brien et al., 2020). More 
recently, as the Covid-19 pandemic stymied this cycle of SSE, the DES issued further guidelines to extend this cycle for another year.

\section{A futile exercise or time well spent?}

LAOS 2016, with minor changes arising from a couple of DES circulars since, remains the current expression and description of what constitutes quality assurance by means of inspection and selfevaluation in Irish schools. In the decades since 2003, the gradual, steady implementation and evolution of the policy set out in that year is most striking, and indeed contrasts starkly with the sudden shifts in policy and practice so common in other jurisdictions and in other aspects of policy in Irish education (Brown et al., 2016c). Huge effort, planning and resources have been invested, but the question remains: Is it worth it? What can we say has been achieved by all of this 'quality assurance'?

In theory, quality assurance is primarily implemented to improve the educational effectiveness of schools (Hofman et al., 2009; TichnorWagner et al., 2017), with a particular focus on improving the quality of instruction (Gelderblom et al., 2016). In order to achieve this, it has been deemed necessary to 'refine formal structures of education systems to streamline decision making, setting ambitious and measurable goals to steer the system in a coherent direction, and engaging a greater variety of stakeholders' (OECD, 2019, p. 144). Is there evidence that these goals have been achieved?

The field of education is one in which it is challenging to ascribe cause and effect. For several years in the 1990s the British government - under the influence of academics, in particular David Hargreaves subscribed to the notion of identifying 'what works', using evidence to drive reform initiatives. Hargreaves describes this as using experiments and randomised research to reach certainty that if we do $\mathrm{x}, \mathrm{y}$ output will result in the form of improved student performance outcomes. Many education specialists were sceptical then and remain so today (Biesta, 2004, 2007, 2009, 2010). The range of variables in any given education system is enormous but, to add to the difficulty, the past thirty years have seen a constant flood of external interventions and 'reforms'. This has led to much talk of 'change fatigue' among schools and teachers, but, of course, also leads to even greater difficulty in saying that any particular initiative has yielded specific and identifiable changes. 
Nonetheless, concerning the policy assurance procedures in Irish schools, the leading architect of school evaluation reform in Ireland, Chief Inspector Hislop, harbours no doubt. In a number of interviews and publications in the 2010s Hislop argued that the combination of SSE and external inspection resulted in a system that improved both school quality and student learning (Brown et al. 2017; Hislop, 2015). In this assertion, Hislop is correct, at least to an extent. For example, a very substantial European-wide study by Ehren et al. (2013) - in which Ireland, through the present authors, was engaged - found that while it was challenging to find a statistically significant relationship between inspection/SSE and student outcomes, it was possible to identify such a link between inspection/SSE and improved school practices, which should, logically, lead to student achievement gains. These practices included teacher collaboration and teamwork, use of a wide range of data for school planning, being influenced by and acting on inspectorial feedback, having to take much greater cognisance of parental and student opinion, and responding to and, to an extent, being pressured by the publication of inspection reports and school plans. Very similar impacts are reported by research in the Irish context (Brown et al., 2018; Young et al., 2018). These two groups of researchers summarised the outcome by saying that while the direct impact of inspection/SSE on student performance was very difficult to quantify, the indirect impact could be shown to be positive and considerable.

Current research by the present authors, due for publication next year, strongly confirms this concept of the indirect influence of the quality assurance regime in Ireland today. Interviews with twenty principals of schools that had undergone inspection since 2016 and had engaged with SSE in the same period threw up very similar themes. Principals were very supportive, almost without exception. This was not because the regime was perceived to be 'light touch' or non-threatening but rather the opposite. It was noted by many principals that, in their view, over time, inspections have become more rigorous, with words like confident, demanding, assertive and, in one case, aggressive being employed to describe inspectorial teams. This, in turn, is perceived by principals as a tool or leverage to force changes which otherwise might be resisted. Taken together with data collection for SSE, principals feel that they have two very useful change drivers: namely hard evidence and the requirements of the Inspectorate to target potentially controversial reforms in their schools such as, for example, driving increased take up of honours subjects among 
'middle-ranking' students and the phasing out of streaming in the school. One principal claimed that the inspection report for the school gave her a blueprint for complete change which could, and would, proceed only because of the prestige of the Inspectorate.

The story then of quality assurance in Irish schools is one of steady and sustained development from modest beginnings over twenty years ago to a well-defined and structured process deeply embedded in the fabric of Irish education today. In the early days McNamara \& O'Hara (2006), in the light of the hostile environment facing school inspection by teacher unions, commented that, like the dog on the bicycle, it was remarkable not that it was being done, even poorly, but that it was being done at all. Twenty years on, whether or not one is convinced that the outcomes justify the resources invested, one can hardly deny that it is a rare example of what can be achieved by steady policy implementation over a sustained period of time (O'Brien et al., 2014, 2017).

\section{References}

Ball, S. J. (1993). What is policy? Texts, trajectories and toolboxes. The Australian Journal of Education Studies, 13 (2), 10-17.

Ball, S. J. (2003). The teacher's soul and the terrors of performativity. Journal of Education Policy, 18 (2), 215-28.

Ball, S. J. (2012). Politics and policy making in education: Explorations in sociology. London: Routledge.

Ball, S. J., Maguire, M., \& Braun, A. (2012). How schools do policy: Policy enactments in secondary schools. London: Routledge.

Ball, S. J., Maguire, M., Braun, A., \& Hoskins, K. (2011). Policy subjects and policy actors in schools: Some necessary but insufficient analyses. Discourse: Studies in the Cultural Politics of Education, 32 (4), 611-24.

Biesta, G. (2004). Education, accountability, and the ethical demand: Can the democratic potential of accountability be regained? Educational Theory, 54 (3), 233-50.

Biesta, G. (2007). Why 'what works' won't work: Evidence based practice and the democratic deficit in educational research. Educational Theory, 57 (1), $1-22$.

Biesta, G. (2009). Good education in an age of measurement: On the need to reconnect with the question of purpose in education. Educational Assessment, Evaluation and Accountability, 21 (1), 33-46.

Biesta, G. (2010). Why 'what works' still won't work: From evidence-based education to value-based education. Studies in Philosophy and Education, 29 (5), 491-503. 
Bowe, R., Ball, S. J., \& Gold, A. (2017). Reforming education and changing schools: Case studies in policy sociology (Vol. 10). London: Routledge.

Boyle, R., McNamara, G., \& O'Hara, J. (2012). Riding the Celtic tiger: Forces shaping evaluation culture in Ireland in good times and bad in evaluation cultures: Sense-making in complex times. London: Transaction Publishers.

Boyle, R., O’Hara, J., McNamara, G., \& Brown, M. (2020). Ireland. In R. Stockmann, W. Meyer, \& L. Taube (Eds), The institutionalisation of evaluation in Europe. London: Palgrave Macmillan.

Brown, M. (2013). Deconstructing evaluation in education. Unpublished thesis, Dublin City University. Retrieved from http://doras.dcu.ie/19382/ [16 November 2020].

Brown, M., McNamara, G., O’Brien, S., Skerritt, C., \& O’Hara, J. (2020). Policy and practice: Including parents and students in school selfevaluation. Irish Educational Studies. doi: 10.1080/03323315.2020.1814839

Brown, M., McNamara, G., \& O'Hara, J. (2013). Nijesh solk mwil start gyamyath (Save us from the time of trial): From austerity to prosperity and back again. 'Educational Policy in Changing Times: Consultation, Implementation and Impact', 38th Annual Conference of the Educational Studies Association of Ireland, University of Limerick, 21-3 March.

Brown, M., McNamara, G., \& O’Hara, J. (2016a). Teacher accountability in education - The Irish experiment. In B. Walsh (Ed.), Essays in the history of Irish education (pp. 359-81). London: Palgrave Macmillan. https://doi.org/10.1057/978-1-137-51482-0_14

Brown, M., McNamara, G., \& O'Hara, J. (2016b). Quality and the rise of value-added in education: The case of Ireland. Policy Futures in Education, 14 (6), 810-29.

Brown, M., McNamara, G., O’Hara, J., \& O’Brien, S. (2016c). Exploring the changing face of school inspections. Eurasian Journal of Educational Research, 66, 1-26.

Brown, M., McNamara, G., O’Hara, J., \& O’Brien, S. (2017). Inspectors and the process of self-evaluation in Ireland. In J. Baxter (Ed.), School inspectors: Policy implementers, policy shapers in national policy contexts (pp. 71-96). Switzerland: Springer. https://doi.org/10.1177\%2F 1478210316656506

Brown, M., McNamara, G., O’ Hara, J., O’Brien, S., Faddar, J., \& Young, C. (2018). Integrated co-professional evaluation? Converging approaches to school evaluation across frontiers. Australian Journal of Teacher Education, 43 (12). http://dx.doi.org/10.14221/ajte.2018v43n12.6

Croxford, L., Grek, S., \& Shaik, F. J. (2009). Quality assurance and evaluation (QAE) in Scotland: Promoting self evaluation within and beyond the country. Journal of Education Policy, 24 (2), 179-93.

Department of Education and Science. (2003). Looking at our school, an aid to self-evaluation in second level schools. Dublin: The Stationery Office. 
Department of Education and Skills. (2012a). School self-evaluation guidelines for post-primary schools. Dublin: Inspectorate of the Department of Education and Skills.

Department of Education and Skills. (2012b). A guide to incidental inspection in second-level schools and centres for education. Dublin: Inspectorate of the Department of Education and Skills.

Ehren, M. C., Altrichter, H., McNamara, G., \& O'Hara, J. (2013). Impact of school inspections on improvement of schools - Describing assumptions on causal mechanisms in six European countries. Educational Assessment, Evaluation and Accountability, 25 (1), 3-43.

Ehren, M., \& Perryman, J. (2018). Accountability of school networks: Who is accountable to whom and for what? Educational Management Administration \& Leadership, 46 (6), 942-59.

Foucault, M. (1995). Discipline and punish: The birth of the prison (2nd edn). New York: Vintage Books.

Gelderblom, G., Schildkamp, K., Pieters, J., \& Ehren, M. (2016). Data-based decision making for instructional improvement in primary education. International Journal of Educational Research, 80, 1-14. https://doi.org/ 10.1016/j.ijer.2016.07.004

Government of Ireland. (2010). Government for national recovery 2011-2016. Dublin: The Stationery Office.

Hislop, H. (2012). The quality assurance of Irish schools and the role of evaluation: Current and future trends. The Professor Seamus Ó Súilleabháin Memorial Lecture 2012, 1 May 2012. Retrieved from

http://www.education.ie/en/Publications/Inspection-Reports-Publications/ Evaluation-Reports-Guidelines/The-Quality-Assurance-of-Irish-Schoolsand-the-Role-of-Evaluation-Current-and-Future-Trends.pdf [12 September 2014].

Hislop, H. (2015). Reflections on leadership challenges in Irish schools. Address by Dr Harold Hislop, Chief Inspector, to the Annual Conference of European Network for Improving Research and Development in Education Leadership and Management. Retrieved from https://www.education.ie/en/PressEvents/Speeches/2015-Speeches/Address-by-Dr-Harold-Hislop-ChiefInspector-Reflections-on-Leadership-Challenges-in-Irish-Schools.pdf [16 November 2020].

HM Inspectorate of Education. (2002). How good is our school? Retrieved from https://x.iriss.org.uk/sites/default/files/resources/063.\%20How\%20 Good $\% 20$ Is \%20Our\%20School\%20-\%20Self\%20Evaluating\%20Using \%20QI\%27s-2001.pdf [16 November 2020].

Hofman, R. H., Dijkstra, N. J., \& Hofman, W. H. A. (2009). School selfevaluation and student achievement. School Effectiveness and School Improvement, 20, 47-68. https://doi.org/10.1080/09243450802664115

Hogan, P. (2019). Preface. In T. Walsh \& R. Doland (Eds), Pushing boundaries, expanding vistas: Celebrating the work of John Coolahan (pp. 5-6). Ireland: Essentra. 
Lynch, K. (2014). New managerialism: The impact on education. Concept, 5 (3), 11.

Lynch, K., Grummell, B., \& Devine, D. (2012). New managerialism in education: Commercialisation, carelessness and gender. New York: Springer.

MacBeath, J. (1999). Schools must speak for themselves: The case for school selfevaluation. London: Routledge-Falmer.

McConnell, A. (2010). Policy success, policy failure and grey areas in-between. Journal of Public Policy, 30 (3), 345-62.

McNamara, G., \& O'Hara, J. (2002). Whole School evaluation and school development planning: An analysis of recent initiatives in Ireland. Educational management administration and leadership, 30, 201-12. https://doi.org/10.1177/02611X02030002510

McNamara, G., \& O'Hara, J. (2004). Trusting the teacher: Evaluating educational innovation. Evaluation, 10 (4), 463-74.

McNamara, G., \& O’Hara, J. (2005). Internal review and self-evaluation - The chosen route to school improvement in Ireland? Studies in Educational Evaluation, 31, 267-82. https://doi.org/10.1016/j.stueduc.2005.11.003

McNamara, G., \& O’Hara, J. (2006). Workable compromise or pointless exercise: School based evaluation in an Irish context. Educational Management, Administration and Leadership, 34 (4), 564-82.

McNamara, G., \& O'Hara, J. (2008a). Contexts and constraints: An analysis of the evolution of evaluation in Ireland with particular reference to the education system. Journal of multidisciplinary evaluation, 4, 75-83.

McNamara, G., \& O'Hara, J. (2008b). Trusting schools and teachers: Developing educational professionalism through self-evaluation (Vol. 8). Bern: Peter Lang.

McNamara, G., \& O'Hara, J. (2008c). The importance of the concept of selfevaluation in the changing landscape of education policy. Studies in educational evaluation, 34 (3), 173-79.

McNamara, G., \& O'Hara, J. (2012). From looking at our schools (LAOS) to whole school evaluation-management, leadership and learning (WSEMLL): The evolution of inspection in Irish schools over the past decade. Educational Assessment, Evaluation and Accountability, 24 (2), 79-97. https://doi.org/10.1007/s11092-012-9143-9

McNamara, G., O’Hara, J., \& Boyle, R. (2008). Influences shaping national evaluation policies: The case of Ireland. The Evaluator, 14, 15-19.

McNamara, G., O’Hara, J., Boyle, R., \& Sullivan, C. (2009). Developing a culture of evaluation in the Irish public sector: The case of education. Evaluation, 15 (1), 101-12.

McNamara, G., O’Hara, J., Lisi, P. L., \& Davidsdottir, S. (2011). Operationalising self-evaluation in schools: Experiences from Ireland and Iceland. Irish Educational Studies, 30 (1), 63-82.

Minogue, M. (1983) Theory and practice in public policy and administration. Policy \& Politics, 11 (1), 63-85. 
O’Brien, S., McNamara, G., \& O'Hara, J. (2014). Critical facilitators. External supports for self-evaluation and improvement in schools. Studies in Educational Evaluation, 43, 169-77.

O’Brien, S., McNamara, G., O'Hara, J., \& Brown, M. (2017). External specialist support for school self-evaluation: Testing a model of support in Irish post-primary schools. Evaluation, 23, 61-79. https://doi.org/10.1177/ 1356389016684248

O’Brien, S., McNamara, G., O'Hara, J., \& Brown, M. (2020). Learning by doing: Evaluating the key features of a professional development intervention for teachers in data-use, as part of whole school selfevaluation process. Professional Development in Education, 1-25.

OECD. (2013). Synergies for better learning: An international perspective on evaluation and assessment. Paris: OECD.

OECD. (2019). Education policy outlook 2019: Working together to help students achieve their potential. Paris: OECD.

Perryman, J. (2006) Panoptic performativity and school inspection regimes: Disciplinary mechanisms and life under special measures. Journal of Education Policy, 21 (2), 147-61.

Sugrue, C. (2006). A critical appraisal of the impact of international agencies on educational reforms and teachers' lives and work: The case of Ireland? European Educational Research Journal, 5 (3-4), 3.

Tichnor-Wagner, A., Wachen, J., Cannata, M., \& Cohen-Vogel, L. (2017). Continuous improvement in the public school context: Understanding how educators respond to plan-do-study-act cycles. Journal of Educational Change, 18, 465-94. https://doi.org/10.1007/s10833-017-9301-4

Young, C., McNamara, G., Brown, M., \& O'Hara, J. (2018). Adopting and adapting: School leaders in the age of data-informed decision making. Educational Assessment, Evaluation and Accountability, 30 (2), 133-58. 